\title{
TANTANGAN MILENIAL DI DESA WISATA
}

Arfah Sahabudin ${ }^{1}$, Rusdin Tahir ${ }^{2}$, M. Sapari Dwi Hadian ${ }^{3}$, Cipta Endyana ${ }^{4}$, Heryadi Rachmat ${ }^{5}$

Program Studi Pariwisata Berkelanjutan

Sekolah Pascasarjana Universitas Padjadjaran

Jl. Dipatiukur nomor 32 Bandung Jawa Barat Indonesia

luluana1.arfah@gmail.com ; rusdin@mail.unpad.ac.id ; sapari@unpad.ac.id ; cipta.endyana@unpad.ac.id ; heryadirachmat220@gmail.com

\begin{abstract}
ABSTRAK
Kaum milenial mendominasi wisatawan di era pariwisata 4.0. Alam dan budaya jika dikemas akan menjadi produk wisata dengan daya pikat menarik bagi wisatawan khususnya wisatawan milenial. Salah satu produk yang dimiliki Indonesia adalah desa wisata atau kampung wisata, dengan atraksi wisata berupa alam dan budaya. Tujuan dari penelitian ini adalah untuk mengungkap potensi digitalisasi desa wisata / kampung wisata untuk dikembangkan menjadi salah satu konsep layanan smart tourism yang mampu menarik wisatawan milenal lebih banyak. Metode penelitian yang digunakan adalah metode kualitatif. Pengumpulan data primernya dilakukan dengan teknik observasi dan wawancara mendalam. Data sekunder dengan studi kepustakaan. Analisis datanya menggunakan model interaktif, melalui tiga kegiatan yang dilakukan bersamaan, yaitu reduksi data, penyajian data, dan penarikan kesimpulan. Hasil penelitian menunjukkan bahwa pemanfaatan teknologi, konsep smart tourism atau digitalisasi desa / kampung wisata merupakan langkah kongkrit yang dapat dilakukan oleh desa wisata / kampung wisata untuk memperbesar peluang kunjungan wisatawan utamanya wisatawan milenial.
\end{abstract}

Kata Kunci : smarttourism, desa wisata, digitalisasi, milenial, era pariwisata 4.0

\section{ABSTRACT}

\section{MILLENNIAL CHALLENGES IN THE TOURIST VILLAGE}

Millennials dominate tourists in the tourism era 4.0. If the nature and culture are packaged, they will become tourist products with an allure to attract tourists, especially millennial tourists. One of the products that Indonesia has is a tourist village, with tourist attractions in the form of nature and culture. The purpose of this research is to reveal the potential of digitizing tourism villages to be developed into one of the concepts of smart tourism services that are able to attract more millennial tourists. The research method used is a qualitative method. Primary data collection is done by observation and in-depth interview techniques. Secondary data with literature study. Data analysis uses an interactive model, through three activities carried out simultaneously, namely data reduction, data presentation, and drawing conclusions. The results showed that the use of technology, the concept of smart tourism or the digitalization of the village / village tourism is a concrete step that can be done by the tourism village / village tourism to increase the chances of tourists visiting mainly millennial tourists.

Keywords: smarttourism, tourism village, digitalization, millennial, tourism era 4.0

\section{PENDAHULUAN}

Indonesia adalah sebuah negara dengan potensi yang melimpah, yaitu berupa potensi alam dan potensi budaya. Kenampakan morfologi yang kompleks dimiliki, dari dataran, perbukitan, hingga gunung. Barat ke Timur dan Selatan ke Utara membentang gugusan pulau yang menjadi potensi di sektor pariwisata. Jumlah pulau yang dimiliki Indonesia mencapai lebih dari 17.000, sejumlah 13.466 pulau sudah bernama dan 11.000 pulau di antaranya sudah berpenghuni. Luas daratan Indonesia di tahun 2014 mencapai $1.919 .440 \mathrm{~km} 2$, sedangkan luas perairannya mencapai $3.257 .483 \mathrm{~km} 2$ dengan garis pantai sepanjang $99.093 \mathrm{~km}$ (LIPI, 2014). Sehingga
Indonesia menurut hasil penelitian dijuluki negara mega biodiversitas dunia yang memiliki keanekaragaman hayati paling tinggi setelah Brazil dengan keunikan, keaslian dan keindahan alamnya (Indrawan, 2007).

Selain alamnya, Indonesia juga memiliki potensi budaya yang melimpah. Terdapat sekitar 250 etnis atau suku diantaranya adalah Gayo, Karo, Minangkabau, Melayu, Bajau, Agam, Serawai, Lampung, Betawi, Banten, Sunda, Kangean, Jawa, Madura, Tengger, Sasak, Flores, Dayak, Banjar, Bugis, Kabaena, Toli-toli, Minahasa, Gorontalo, Taliabu, Misool, Biak, Asmat, dan masih banyak lagi (Kemendikbud, 2018). 
Artinya Indonesia adalah negara dengan berbagai macam alternatif pilihan untuk dikunjungi wisatawan. Alam dan budaya jika dikemas akan menjadi produk wisata dengan daya pikat menarik bagi wisatawan lokal dan mancanegara. Salah satu produk yang dimiliki Indonesia adalah desa wisata atau kampung wisata, dengan atraksi wisata berupa alam, budaya dan buatan. Desa wisata adalah satu wilayah administratif atau lebih dengan batasan tertentu yang memiliki produk wisata dengan pengelolaan dilakukan oleh masyarakat lokal.

Di Indonesia terdapat 74.957 desa, dengan 270 kawasan pedesaan, 122 daerah tertinggal, 619 kawasan transmigrasi, 54 Kabupaten rawan pangan, 41 Kabupaten rawan konflik, 58 Kabupaten memiliki pulau kecil dan terluar, 90 Kabupaten rawan bencana (Kemendes, 2018). Indonesia juga memiliki 1.302 desa wisata, dengan 6 peringkat teratas adalah 138 Jawa Barat, 132 Jawa Tengah, 114 Jawa Timur, 92 NTT, 87 Sumatera Utara, dan 57 DIY (Kemendikbud, 2016).

Berbagai pendekatan menjadi latar belakang tumbuh dan berkembangnya desa wisata di Indonesia. Misalnya adalah masalah-masalah kesejahteraan masyarakat dan kurangaktifnya keterlibatan masyarakat di sektor pariwisata. Untuk menangani hal tersebut diperlukan upaya pemberdayaan masyarakat yang salah satu pendekatannya melalui pariwisata. Selain masalah, hal positif juga dijadikan latar belakang dalam pengembangan desa menjadi desa wisata. Misalnya saja kondisi alam yang memang sudah memiliki nilai lebih, mempertahankan kearifan lokal kemudian dijadikan sebagai atraksi wisata, dan pelestarian lingkungan untuk menjaga kondisi alam tetap berkelanjutan. Dan agar memperoleh hasil dari adanya desa wisata maka perlu adanya kunjungan dari wisatawan.

Di Provinsi Banten tahun 2019 tercatat 40 Desa / Kampung Wisata (Dispar Banten, 2019). Dengan pembinaan Kelompok Sadar Wisata sebagai bentuk pemberdayaan masyarakatnya yang terbentuk atas swadaya dan swakarsa masyarakat yang menjadi motivator, penggerak dan mitra pemerintah yang dalam aktifitasnya berupaya utuk meningkatkan kepahaman kepariwisataan, meningkatkan peran dan partisipasi dalam pembangunan kepariwisataan, meningkatkan nilai manfaat kepariwisataan bagi anggota dan masyarakat.

Wisatawan adalah individu atau kelompok yang melakukan perjalanan dengan batasan wilayah dan waktu tertentu dengan tujuan untuk melakukan aktivitas wisata. Perputaran ekonomi yang dihasilkan dari adanya wisatawan yang berkunjung di desa wisata dengan membeli paket-paket wisata yang ditawarkan akan menambah penghasilan masyarakat. Wisatawan selama di desa wisata akan membelanjakan uang untuk berbagai hasl, seperti membeli makanan, minuman, oleh-oleh, membayar transportasi lokal, dan pengeluaran lainnya yang sifatnya adalah untuk memenuhi kebutuhannya. Hal seperti inilah yang dijadikan peluang oleh pengelola desa wisata dalam meningkatkan keuntungan pendapatan. Pendapatan lainnya berasal dari produk yang ditawarkan oleh pengelola kepada wisatawan bersama paket-paket wisata.

Berbagai motivasi wisatawan untuk berlibur saat ini mengalami perubahan. Sebuah survey menyatakan $83 \%$ ingin liburannya tidak merusak lingkungan, $71 \%$ ingin agar liburannya bisa memberikan keuntungan bagi masyarakat setempat, $54 \%$ ingin tahu lebih banyak tentang berbagai isu sosial budaya dan lingkungan lokal sebelum mereka memesan tiket liburannya, $77 \%$ ingin agar dalam liburannya dapat mencicipi makanan dan budaya lokal (ABTA annual survey, 2008).

Berbagai macam karakteristik wisatawan saat ini juga bermunculan, dari wisatawan ramah lingkungkan, wisatawan backpacker, hingga wisatawan milenial. Wisatawan milenial memiliki beberapa kriteria, diantaranya adalah umur, asal daerah, pekerjaan, pendapatan, konektifitas, frekuensi perjalanan, biaya perjalanan, dan motivasi. Wisatawan milenial di dominasi oleh kelompok yang diberi nama Generasi Y yaitu wisatawan dengan umur 17-25 tahun. Wisatawan milenial sebagian besar berasal dari daerah yang mengalami perkembangan pesat seperti perkotaan dengan kemudahan akses pada teknologi.

Wisatawan milenial dapat secara mandiri mengatur perjalanannya karena keberanian menggunakan teknologi untuk mencari informasi terkait destinasi wisata yang akan dikunjunginya. Biasanya wisatawan milenial akan mencari destinasi wisata yang tergolong masih baru dan belum banyak yang mengunjungi. Mereka cenderung lebih memilih megunjungi destinasi bersama teman-teman seumurnya atau bahkan secara individu.

Sedangkan menurut penelitian tentang wisatawan milenial di Bali yang dilakukan oleh Parhusip dan Arida tahun 2018 menyebutkan Sebanyak 73\% wisatawan milenial di Bali memilih akan mengalokasikan pendapatannya untuk sebuah pengalaman liburan dibandingkan dengan kepemilikan materialistik, dan menunjukkan perjalanan wisata adalah prioritas dalam pengalokasian pendapatannya.

Mareta Puspa Nagari Edriana Pangestusi (2019), menulis tentang Peran Digital Tourism Dalam Pengembangan Kampung Wisata Jodipan. Digital tourism memerlukan suatu atraksi yang memenuhi kebutuhan wisatawan akan kegiatan berfoto sehingga memberikan hasil gambar yang bagus untuk diunggah di media sosial. Peran mandiri dan aktif oleh 
masyarakat lokal dan antusiasme masyarakat dapat menghalau kendala-kendala penghambatnya.

Media Sosial bagi Desa Wisata: Sebuah Kajian Konseptual Oleh Stevanus Wisnu Wijaya (2016). Membahas tentang bagaimana peran media sosial bagi bisnis pariwisata desa wisata. Kemampuan sumber daya manusia dalam penggunaan TIK termasuk aplikasi media sosial yang masih rendah memerlukan pendekatan yang mampu meningkatkan literasi media sosial untuk industri pariwisata, khususnya industri skala kecil seperti desa wisata.

\section{METODE}

Metode penelitian yang digunakan adalah metode kualitatif. Pengumpulan data primernya dilakukan dengan teknik observasi dan wawancara mendalam. Data sekunder dengan studi kepustakaan yaitu suatu teknik pengumpulan data dengan menghimpun dan menganalisis dokumen-dokumen, baik dokumen tertulis, gambar maupun elektronik Analisis datanya menggunakan model interaktif, melalui tiga kegiatan yang dilakukan bersamaan, yaitu reduksi data, penyajian data, dan penarikan kesimpulan.

\section{HASIL DAN PEMBAHASAN}

Motivasi bagi wisatawan milenial untuk melakukan perjalanan adalah untuk mencari hal menarik, bertemu dengan orang baru, mencoba makanan baru, bersantai sejenak, menikmati pemandangan, mengunjungi tempat mengesankan, berpetualangan dengan merasakan cara hidup yang berbeda, mengunjungi teman di daerah lain, mengikuti acara olahraga, dan mengunjungi negara-negara dengan biaya yang terjangkau.

Salah satu yang mencerminkan makna perjalanan wisatawan milenial adalah pencarian jati diri, melakukan perjalaan wisata bukan hanya sekedar fisik saja tetapi bagaimana sikap terhadap orang lain. Milenial juga memaknai perjalanan wisata adalah ingin lebih mengenal diri sendiri bertemu dengan orang banyak, serta ingin melihat hidup dari sudut pandang yang berbeda, serta meninggalkan aktivitas sejenak di daerah asal untuk menikmati waktu untuk lebih mengenal kelemahannya dan sejenak untuk menyenangkan jiwa.

Selanjutnya makna yang didapat wisatawan milenial ketika melakukan perjalanan adalah ingin melihat lebih banyak lagi pemandangan baru, budaya baru serta ingin mendapatkan pengalaman yang luar biasa sehingga dapat mengembangkan cara pandang baru; untuk berinvestasi, bukan dalam bentuk materi tetapi investasi kebahagiaan merefresh pikiran, serta ingin lebih menikmati masa muda.

Beberapa wisatawan milenial melakukan traveling adalah untuk menunjukkan keorang lain, pamer, rasa lebih meningkatkan harga diri, dan tidak mau hidup yang biasa-biasa saja, ingin mendapatkan kebahagiaan yang berbeda atau pun sekedar ingin menunjukkan kualitas diri.

Karakteristik wisatawa milenial (UNWTO, 2014 dalam The Future Fondation, (2016)) yaitu,

1. Milenial adalah manusia dengan ketergantungan teknologi akut. Bagi mereka konektivitas adalah segalanya. Dalam berwisata mereka membutuhkan teknologi dalam segala hal aspek. Mulai dari mendapatkan ide akan berwisata kemana, mencari informasi hingga memamerkan perjalanannya.

2. Kaum milenial adalah Promotor Destinasi. Ibarat freelacer marketer sebuah destinasi. Mereka akan degan sukarela mempromosikan destinasi yang dikunjunginya di media sosial.

3. Kontroler akut. Mereka ingin mengeksplor secara bebas tanpa ada rasa dipaksa atau diatur. Cenderung lebih suka tidak ikut paket tur.

4. Memburu pengalaman baru adalah tujuan utama. Mereka akan berwisata seolah menjadi penduduk lokal, mulai dari kuliner, cara hidup dan lain-lain.

5. Milenial merupakan Periset handal. Mereka lebih lama menghabiskan waktu untuk mensurvey harga, tujuan wisata dan informasi yang diinginkan dari kaum sebelumnya.

6. Milenial adalah Petualang instagenic. Tujuan utama perjalaan mereka adalah selain pengalaman baru adalah "seistagramable apakah guwe?"

7. Milenial merupakan Smart spender. Kurang budget tidak menjadi halangan bagi kaum ini untuk berwisata kemana pun. Ada Teknik patungan sesame mereka dan pemanfaatan open trip yang sedang marak.

Apa yang dicari wisatawan milenial ? Future Fondation (2016) merangkumnya dalam Millenial \& Future of Travel, yaitu

1. Kaum milenial dalam berwisata cenderung akan mencari pengalaman yang otentik. Mereka punya cita rasa tiggi terhadap wisata yang otentik, orisinil, non-mainstream dan yang dapat memberikan pengalaman hidup seolah sebagai orang lokal. 
2. Kaum milenial dalam berwisata merupakan proses validasi sosial. Mereka gemar memburu tempat-tempat yang unik atau surga tersembunyi. Lalu pengalaman ini yang mereka bagikan di sosial media untuk medapatka pegnakuan dari teman-teman jejaringnya.

3. Ternyata kaum milenial mengutamakan kenyamanan ketika mereka berwisata. Termasuk masalah kebersihan da keamanan.

Karakteristik dan motivasi yang menjadi latar belakang wisatawan milenial untuk berlibur dapat dimanfaatkan oleh desa wisata dalam melakukan segmentasi pasar. Segmentasi pasar adalah aktivitas membagi suatu pasar menjadi kelompok-kelompok pembeli yang berbeda dengan kebutuhan, karakteristik, dan perilaku yang berbeda sehingga membutuhkan produk yang berbeda.

Pengelola desa wisata dapat mengambil peluang yang ada dengan menciptakan produk-produk kekinian yang ramah dengan wisatawan milenial.

Adanya kesamaan dalam hal latar belakang antara wisatawan milenial dengan desa wisata, akan semakin memperbesar peluang kunjungan wisatawan milenial ke desa wisata. Berbagai pembenahan perlu dilakukan untuk menangkap peluang tersebut harus dilakukan oleh pengelola, misalnya dalam hal media pemasaran secara online, kemudahan akses dalam memesan dan membayar produk desa wisata, branding desa wisata untuk mempengaruhi minat wisatawan milenial, dan adanya peningkatan sumberdaya manusia untuk pemanfaatan teknologi di desa.

Salah satu langkah kongkrit dapat dilakukan oleh desa / kampung wisata untuk memperbesar peluang kunjungan wisatawan milenial adalah dengan pemanfaatan teknologi. Desa / kampung wisata secara kolektif dapat membuat platform digital yang nantinya berfungsi sebagai pemberi informasi, penerimaan pembayaran, ticketing dan interaksi secara online dengan pengelola. Jumlah pengunjung akan terdata secara online.

Pengguna internet di Indonesia menurut Kominfo tahun 2018 masuk peringkat 6 besar dunia sampai tahun 2018. Sumber lainnya di apji.or.id menyebutkan $143,26 \mathrm{M}$ pengguna internet dari $262 \mathrm{M}$ jumlah penduduk Indonesia. Kemenpar tahun 2018 berpendapat bahwa $63 \%$ kegiatan travelling saat ini dicari, dipesan dan dijual secara online dan $50 \%$ dari penjualan online travel menggunakan lebih dari satu gadget, bahkan sekitar 200 lebih ulusan mengenai travelling permenitnya telah diposting di TripAvisor.2019-08-

Gaya Smart Traveling saat ini dengan perkembangan digitalisasi sudah sangat memudahkan para wisatawan untuk mencari rekomendasi destinasi wisatanya. Google mencipatakan fitur Local Guides dimana para user diajak untuk berkontribusi untuk mengumpulkan informasi sebanyak mungkin tentang apapun yang ada di internet dengan sistem reviews.

Nantinya ini akan memudahkan para traveler untuk mencari rekomendasi tempat wisata mana yang bagus di suatu daerah, rekomendasi tempat makan apa yang khas di tempat tersebut, bahkan kita bisa melihat bagaimana keindahan lokasi tersebut melalui foto \& video yang di unggah.

Instagram bisa dikatakan telah mengendalikan hidup milenial. Instagramable telah menjadi sebuah "standar". Segala jenis bisnis di era milenial ini jika ingin sukses harus bisa memenuhi standar tersebut. Pola perilaku user di Instagram bisa dijelaskan sebagai hasil triadic reciprocal.

Instagram memanfaatkan aspek psikologis manusia yang "haus" pengakuan. Milenial senang berbagi apapun di sosial media dan Instagram menjadi panggung untuk mereka show off. Tanpa disadari, Instagram telah membentuk konstruksi berpikir yang membentuk habit. Situasi ini yang kemudian melahirkan fenomena-fenomena bisnis seperti kafe, rumah, destinasi wisata, OOTD (Outfit of The Day), hingga resepsi pernikahan harus instagrammble.

\section{SIMPULAN}

Pemesanan Transportasi online, tiket online dan paket wisata serta akomodasi online realtime dan yang staycation, promosi-promosi menarik, pembayaran yang praktis (digital payment) dan cashier less yang dapat diakses dengan mudah lewat aplikasi, dan pastinya Instagramable adalah salah satu cara "menjual" desa wisata dan agar menarik untuk dikunjungi.

Selain pemanfaatan teknologi, langkah kongkrit yang harus dilakukan agar sebuah destinasi wisata yang disebut Desa / Kampung Wisata, sesuai pangsa pasar terbesar saat ini yang dapat dibidik sebagai target pengunjung dan wisatawan terbesar, maka produk yang akan kita "jual" dan sajikan adalah mesti sesuai dengan karakter dan perilaku milenial. Tidak cukup hanya dengan menyediakan sarana prasarana dan daya tarik, tapi harus menciptakan desa wisata memiliki kelebihan yang tidak dimiliki tempat lain, sehingga menarik calon pengunjung untuk datang, yaitu experient, connection \& memorable moment. Singkatnya, destinasi wisata harus MILLENIAL FRIENDLY. 


\section{DAFTAR PUSTAKA}

\section{Pustaka yang berupa Handbook:}

The Future Fondation., (2016). The Future of Tourism. Millenial \& Future of Travel.

Kemendes, (2018). Laporan Kinerja 2018. Kementrian Desa, PDT dan Transmigrasi

LIPI,(2014). Kekinian Keanekaragaman Hayati Indonesia.

Pusat Data Dan Statistik Pendidikan Dan Kebudayaan (Pdspk), (2016). Kementrian Pendidikan Dan Kebudayaan.

Yuswhady, Dkk. (2019). Marketing Outlook 2020.

. Invent.Ure.

\section{Pustaka yang berupa Artikel Jurnal:}

Indrawan, Mochamad dkk. (2007). Biologi Konservasi. Yayasan bina sains Hayati Indonesia. Jakarta.

Mareta Puspa Nagari Edriana Pangestusi (201), Peran Digital Tourism Dalam Pengembangan Kampung Wisata Jodipan. Jurnal Administrasi Bisnis (JAB)|Vol. 74 No. 1 September 2019

Parhusip, N., \& Arida, I. (2019). Wisatawan Milenial Di Bali. Jurnal Destinasi Pariwisata, $6(2), 299$ - 303. Doi: 10.24843/Jdepar 2018.V06.I02.P14
Sastrawan I., Paturusi, S., \& Arida, N. (2017). Evaluasi Pengembangan Potensi "Ancient Track One" dengan model Cipp di Desa Wisata Bedulu dan Desa Buruan Kabupaten Gianyar. Jurnal Master Pariwisata (Jumpa, Doi:10.24843/Jumpa2017.V04.I01.P10

Stevanus Wisnu Wijaya (2016). Media Sosial bagi Desa Wisata. Media Teknika Jurnal Teknologi Vol. 11, No. 1, Juni 2016.

\section{Pustaka dari website:}

https://www.halodoc.com/ Fintech Reports, Daily Social (2019)

Understanding Indonesia's Online Food Market, Nielsen (2019)

freshome.com Fintech Reports, Daily Social (2019) 